\title{
INVENTARISASI DONGENG HANTU \\ DI KECAMATAN NAGRAK KABUPATEN SUKABUMI \\ UNTUK BAHAN PEMBELAJARAN MEMBACA DI SMP
}

\author{
An-nisa Nur Maulida, Ruhaliah, Rétty Isnéndés \\ Jurusan Pendidikan Bahasa Daerah FPBS UPI \\ Pos-el: anurmaulida@gmail.com, ruhaliah@upi.edu, retty.isnendes@upi.edu
}

\begin{abstract}
Abstrak
Skripsi ini bertujuan untuk mendeskripsikan dongeng hantu, mengklasifikasikan dongeng hantu, menganalisis struktur cerita dongeng hantu, dan mengaplikasikannya untuk bahan ajar membaca di SMP. Penelitian ini menggunakan metode deskriptif analitik dengan teknik studi pustaka, observasi, dan wawancara. Populasi dalam penelitian ini menggunakan populasi wilayah, sedangkan sumber datanya adalah seluruh dongeng. Dongeng hantu yang berhasil dikumpulkan dari tujuh narasumber sebanyak delapanbelas dongeng. Setelah dideskripsikan,dongeng hantu selanjutnya diklasifikasikan. Klasifikasi delapan belas dongeng hantu tersebut terdiri atas: lima dongeng "ririwa", dua dongeng hantu, dan sebelas dongeng lainnya termasuk dongeng siluman. Analisis dongeng mencakup: tema, alur, latar, dan tokoh. Dari analisis tersebut dapat disimpulkan bahwa tema dari semua dongeng hantu adalah tema sosial. Tujuh dongeng memiliki galur maju, sedangkan satu dongeng lainnya termasuk alur campuran. Pelaku dalam dongeng seluruhnya manusia. Latar tempat dalam delapan dongeng yang dianalisis adalah empat dongeng berlatar di rumah, tiga dongeng berlatar di hutan, dan satu dongeng berlatar di sungai. Adapun latar waktu sebanyak tujuh dongeng berlatar waktu siang hari. Sebagian berlatar waktu sore dan malam hari. Dongeng yang sesuai untuk bahan ajar membaca kelas VII sejumlah delapan dongeng. Pelestarian dongeng oleh pemerintah dan masyarakat dengan cara membukukan dongeng ataupun menceritakan kembali dongeng ke generasi selanjutnya mungkin akan menjadi salah satu cara yang tepat agar kita tidak kehilangan nilai budaya dan tradisi di daerah kita sendiri.
\end{abstract}

Kata kunci: dongeng jurig, pangajaran maca

\section{INVENTORIES OF GHOST'S FOLKTALE AT SUB DISTRICT NAGRAK THE REGENCY OF SUKABUMI FOR READING TEACHING IN JUNIOR HIGH SCHOOL}

\begin{abstract}
This research was conducted based on a background to described, classified, and analyzed ghost's folktale then applied it for reading teaching in Junior High School. This research used descriptive analytic's method with literature written, observation, and interview's techniques. The population in this research was region population and data source was folktales. There was eighteen folktales from seven correspondences. After we described it all, we can classified that five folktales are "ririwa" folktales, two folktales are ghost folktales, and eleven folktales was "siluman" folktales.. Folktale's analyzed included: theme, plot, setting, and character. All of theme in the folktale are social theme. Seven folktales are chronological plot, and one folktale is chronological-reverse plot. All characters are human. Place setting mostly at home, three folktales at jungle, and one folktale at the river. Time setting mostly at noon, some folktales are happened at afternoon and night. Eight folktales are suitable for reading teaching Taking responsibility by
\end{abstract}


government and citizen to re-telling folktales for the next generation become one of the way to make culture belongs to life.

Keywords: ghost's folkltale, reading teaching

\section{PENDAHULUAN}

Bahasa merupakan alat komunikasi dan merupakan unsur kebudayaan masyarakat. Berikut tujuh unsur kebudayaan menurut Koentjaraningrat (1993 hal. 2): 1) sistem religi dan upacara keagamaan, 2) sistem organisasi dan kemasyarakatan, 3) sistem pengetahuan, 4) bahasa, 5) kesenian, 6) sistem pekerjaan, dan 7) sistem teknologi. Selain termasuk salah satu unsur kebudayaan, bahasa memiliki fungsi penting yaitu alat berekspresi untuk kepuasan rasa, emosi, dan batin yang dituangkan melalui karya sastra.

Berdasarkan wujudnya, karya sastra Sunda diklasifikasikan menjadi tiga, yaitu puisi, prosa, dan drama. Sedangkan, berdasarkan waktunya, karya sastra Sunda terbagi menjadi sastra Sunda baru dan sastra Sunda lama.

Salah satu karya sastra Sunda dalam bentuk prosa adalah dongeng. Dongeng sering disebut juga folktale atau cerita rakyat. Disebut cerita rakyat, sebab dongeng menyebar secara lisan, tidak diketahui siapa pengarangnya (anonim), dan mengandung unsur ketidakmungkinan.

Menurut Isnendes (2010 hal. 25) dongeng dibagi menjadi 7 jenis, yaitu: 1) fabel (dongeng hewan), 2) pamuk (dongeng orang yang tidak biasa), 3) mite (dongeng dewa), 4) sage (dongeng pahlawan), 5) legenda, 6) sasakala, dan 7) dongeng hantu.

Karya sastra lisan khususnya dongeng, erat kaitannya dengan aspek membaca. Hodgson dalam Tarigan (2008 hal. 7) menjelaskan bahwa membaca adalah suatu proses yang dilakukan serta dipergunakan oleh pembaca untuk memperoleh pesan, yang hendak disampaikan oleh penulis melalui media kata-kata/bahasa tulis. Anderson (1972: 214) dalam Tarigan (2008 hal. 9-10) menjelaskan bahwa tujuan utama membaca adalah untuk mendapatkan informasi yang meliputi isi dan memahami arti bacaan.

Di zaman modern seperti sekarang, hal yang berbau misteri masih menjadi hal yang menarik untuk masyarakat. Contoh saja acara televisi "Masih Dunia Lain" dan "Dua Dunia" yang memiliki rating tinggi atau siaran radio "Nightmare Side" yang setia didengar meski acaranya di malam hari. Bila dikaitkan dengan hal misteri, kita pun memiliki jenis karya sastra dongeng hantu yang tak kalah menariknya dengan acara siaran televisi dan radio. Dongeng hantu bisa menjadi dongeng yang menarik baik di kalangan anak-anak, remaja, atau dewasa, karena seperti dikatakan Suherman (2010) masyarakat masih menyukai cerita mistis (lalakon aheng) seperti alam gaib atau supranatural. Hal itulah yang mendorong peneliti untuk meneliti dongeng hantu lebih lanjut.

\section{METODE}

Metode yang digunakan dalam penelitian ini adalah metode deskriptif.

Menurut Suyatna (2002 hal. 14) metode yang menggunakan metode deskriptif merupakan penelitian yang mengakumulasikan data dasar hanya dengan deskriptif saja, tidak menggunakan hipotesis dan tidak ada makna implikasi.

Desain atau langkah-langkah dalam penelitian ini, yaitu: 
Identifikasi Masalah

1. Kasang Tukang Masalah

2. Rumusan Masalah

3. Tujuan Penelitian

4. Anggapan Dasar

5. Metode Penelitian

Menyusun Laporan Penelitian jeung Kesimpulan

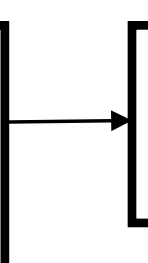

1. Studi pustaka

2. Observasi

3. Wawancara

\section{Mengolah Data}

1. Inventarisasi dongeng hantu di Kecamatan Nagrak

2. Analisis struktur dongeng hantu di Kecamatan Nagrak

3. Cocok atau tidaknya untuk bahan ajar membaca dongeng di SMP
Sumber data dalam penelitian ini yaitu tujuh narasumber dari dua desa yang berbeda. Dalam proses mengumpulkan data, penelitian dilakukan dengan menggunakan teknik observasi, wawancara, dan dokumentasi.

\section{HASIL DAN PEMBAHASAN}

Penelitian dilakukan di Kecamatan Nagrak Kabupaten Sukabumi. Dari hasil penelitian, dongeng yang terkumpul sejumlah tiga puluh delapan dongeng. Delapan belas dongeng diantaranya merupakan dongeng hantu.

Dongeng hantu tersebut adalah: 1) "Nyai Kabaya Hejo ti Kuta Weusi",2) "Panon Coplok",3) "Gagara Tangkal Jeungjing Laut",4) "Siluman Kuda",5) "Hantu Gegep",6) "Hantu Lauk Emas",7) "Hantu Baralak”,8) "Nu Palid di Cikolawing”,9) "Mindahkeun Makam”, 10) "Batu Korsi",11) “Batu Panjang”,12) "Makam Kabayan",13) "Ratu Kunti”,14) "Oray Gorolong di Cidopang”, 15) "Oray Cisarongge", 16) "Dukuh Nara", 17) "Lini Sakapeung", dan 18) "Caah di Ciguling Jawa".Delapan belas dongeng tersebut seluruhnya dideskripsikan dalam bentuk cerita.

Dari hasil deskripsi tersebut, kita bisa mengklasifikasikan dongeng hantu berdasar wujud hantunya ke dalam tiga jenis. Klasifikasi dongeng hantu tersebut adalah: (1) dongeng ririwa, (2) dongeng hantu, dan (3) dongeng siluman. Dongeng ririwa adalah dongeng yang menceritakan hantu yang mati dalam keadaan tidak wajar. Ririwatidak nampak dengan kasat mata dan tidak pernah menampakkan diri seperti hantu-hantu yang lain. Ririwabiasanya hanya hadir lewat mimpi atau dalam bentuk suara saja. Dongeng hantu adalah dongeng yang menceritakan hantu yang biasa dikenal di Indonesia, contohnya: kuntilanak, pocong, genderuwo, tuyul, kalong wewe, dan sebagainya. Hantu tersebut biasa menampakkan diri sebagai sosok yang seram sesuai ciri khasnya. Contohnya: kuntilanak dengan rambut panjang dan baju putihnya, genderuwo dengan badannya yang tinggi besar dan berkulit hitam legam, tuyul dengan perawakannya yang kecil dan botak, dan lain-lain. Adapun dongeng siluman, adalah dongeng yang menceritakan hantu yang berubah wujud atau dalam Bahasa Sunda disebut nyaru. Siluman ini tidak berubah menjadi manusia, melainkan berubah wujud menjadi hewan, tumbuhan, dan penyakit. Siluman yang berubah wujud menjadi hewan contohnya siluman ular, siluman kuda, atau siluman buaya. Ada pula siluman yang berubah wujud menjadi tumbuhan daun kelapa kering atau dalam Bahasa Sunda disebut baralak. Hal yang tidak banyak diketahui orang adalah adanya siluman yang berubah wujud 
menjadi penyakit, contohnya hantu lauk emas. Siluman ini nyaru menjadi penyakit kulit yang membuat penderitanya gatalgatal setiap anggota tubuhnya digaruk. Ada pula hantu gegep yang sering menyerang bayi, mengakibatkan bayi tersebut kejang seolah-olah seperti sedang menggigit gegep.

Dari hasil deskripsi dan klasifikasi, dipilih delapan dongeng yang tepat untuk dianalisis unsur intrinsiknya. Unsur intrinsik yang dianalisis terdiri atas tema, alur, latar, dan pelaku. Dari hasil analisis tersebut, seluruh dongeng yang dianalisis bertema sosial yang menceritakan bagaimana berhubungan antara manusia dengan manusia atau manusia dengan makhluk lainnya. Alur terbagi menjadi tiga jenis, yaitu: alur maju, alur mundur, dan alur campuran. Dalam delapan dongeng yang dianalisis, ujuh dongeng alurnya maju dan satu dongeng alurnya campuran. Pelaku utama dalam dongeng yang dianalisis seluruhnya manusia. Unsur intrinsik selanjutnya yaitu latar. Latar terbagi dua, yaitu latar waktu dan latar tempat. Latar waktu cerita mistis yang biasanya identik terjadi di malam hari, berbeda dengan latar waktu yang ada dalam dongeng ini. Latar waktu dalam delapan dongeng yang dianalisis, dominan bercerita di siang hari. Dalam beberapa dongeng ditemukan latar waktu malam, tapi latar waktu malam disebutkan hanya sekilas. Latar tempat pun dominan berada di rumah, tidak di kuburan atau hutan seperti yang banyak diceritakan dalam televisi.

Berdasarkan hasil deskripsi, klasifikasi, dan analisis dongeng. Dari delapan belas dongeng hantu, ada delapan dongeng yang bisa dijadikan bahan ajar membaca untuk siswa kelas VII SMP, yaitu: 1) "Gara-gara Tangkal Jeungjing Laut", 2) "Panon Coplok", 3) "Nu Palid di Cikolawing", 4) "Nyai Kabaya Hejo ti Kuta Weusi", 5) " Lini Sakapeung", 6) "Dukuh Nara”, 7) "Siluman Kuda", jeung8) "Ratu Kunti". Menurut Rahman (2011 hal. 16), salah satu kriteria bahan ajar yang baik adalah bisa menarik minat siswa, dan memiliki transfer nilai. Delapan dongeng hantu di atas memenuhi kriteria bahan ajar karena unsur intrinsiknya lengkap. Selain bisa menarik minat siswa, dongeng hantu tidak hanya memiliki unsur misteri saja, tetapi mengandung nilai-nilai kemanusiaan yang bisa menjadi bahan pembelajaran moral bagi para pembacanya.

\section{SIMPULAN}

Dari 38 dongeng yang terkumpul di Kecamatan Nagrak Kabupaten Sukabumi, ada 18 dongeng yang bergenre hantu. Menurut Kamus Umum Bahasa Sunda (2007 hal. 192) dan Kamus Basa Sunda karya Satjadibrata (2005 hal. 177) hantu adalah arwah yang sering mengganggu manusia atau sering membuat celaka. Dongeng hantuyang terkumpul kemudian dideskripsikan, diklasifikasi, dianalisis unsur intrinsiknya, dan disimpulkan apakah dongeng hantu bisa diaplikasikan menjadi bahan ajar membaca kelas VII SMP.

Dari hasil penelitian, inventarisasi dongeng hantu di Kecamatan Nagrak Kabupaten Sukabumi dapat disimpulkan seperti di bawah ini:

1) Terdapat 18 dongeng hantu yang dideskripsikan, yaitu: (1) "Nyai Kabaya Hejo ti Kuta Weusi", (2) "Panon Coplok", (3) "Gagara Tangkal Jeungjing Laut", (4) "Siluman Kuda", (5) "Hantu Gegep”, (6) "Hantu Lauk Emas", (7) "Hantu Baralak", (8) "Nu Palid di Cikolawing", (9) "Mindahkeun Makam”, (10) "Batu Korsi”, (11) "Batu Panjang", (12) "Makam Kabayan", (13) "Ratu Kunti", (14) "Oray Gorolong di Cidopang", (15) "Oray Cisarongge", (16) "Dukuh Nara", (17) "Lini Sakapeung”, dan (18) "Caah di Ciguling Jawa".

2) Klasifikasi dari delapan belas dongeng hantu tersebut adalah: (1) lima dongeng termasuk dongeng ririwa, (2) dua dongeng termasuk 
dongeng hantu, dan (3) sebelas dongeng termasuk dongeng siluman.

3) Unsur intrinsik yang dianalisis dalam dongeng adalah: tema, latar, pelaku, dan alur. Seluruh dongeng yang dianalisis bertema sosial. Tujuh dongeng yang dianalisis alurnya maju dan satu dongeng alurnya campuran. Pelaku utama dalam dongeng yang dianalisis seluruhnya manusia. Latar waktu dalam delapan dongeng yang dianalisis, dominan bercerita di siang hari. Latar tempat pun dominan berada di rumah, tidak di kuburan atau hutan seperti yang banyak diceritakan dalam televisi.

4) Berdasarkan hasil penelitian, dongeng hantu yang berjudul:1) "Gara-gara Tangkal Jeungjing Laut", 2) "Panon Coplok", 3) "Nu Palid di Cikolawing", 4) "Nyai Kabaya Hejo ti Kuta Weusi”, 5) “ Lini Sakapeung”, 6) "Dukuh Nara”, 7) "Siluman Kuda", jeung 8) "Ratu Kunti" cocok diaplikasikan sebagai bahan pengajaran membaca di SMP, sebab memenuhi kriteria bahan ajar.

Dongeng hantu sebagai bahan ajar diharapkan bisa meningkatkan ketertarikan siswa pada materi ajar membaca dan meningkatkan siswa pada kesadaran berbudaya dengan cara menggunakan budaya tersebut dalam kehidupan sehariharinya.

\section{PUSTAKA RUJUKAN}

Koentjaraningrat. (1993). Kebudayaan Mentalitas dan Pembangunan. Jakarta: PT Gramedia Pustaka Utama.

Isnendes, R. (2010). Teori Sastra. Bandung: JPBD FPBS UPI.

Panitia Kamus Lembaga Basa jeung Sastra Sunda. (2007). Kamus Umum Basa Sunda. Bandung: Geger Sunten.

Rahman. (2011). Model Mengajar \& Bahan Pembelajaran. Bandung: Alqa Prisma Interdelta.

Satjadibrata, R. (2005). Kamus Basa Sunda. Bandung: PT Kiblat Buku Utama.

Suherman, A. (2010) Ngislamkeun Siluman. Cupumanik, No. 231.

Suyatna, A. (2002). Pengantar Metodologi Penelitian Pendidikan dan Pengajaran Bahasa. Bandung: Departemen Pendidikan Nasional UPI FPBS Jurusan Pendidikan Bahasa Indonesia dan Daerah.

Tarigan, H. G. (2008). Membaca Sebagai Suatu Keterampilan Berbahasa. Bandung: Angkasa.

\section{UCAPAN TERIMA KASIH}

Terima kasih kepada pengelola jurnal Lokabasa yang telah menerbitkan tulisan ini, serta kepada penulis terdahulu yang karya atau bukunya dikutip dalam tulisan ini. 